\title{
Misconceptions Of Employee Turnover: Evidence-Based Information For The Retail Grocery Industry
}

Steven Harrison, University of Phoenix, USA

Pamela Ann Gordon, University of Phoenix, USA

\begin{abstract}
Employee turnover rates are higher in the retail grocery industry in comparison to other industries. This level of turnover produces demoralizing effects on the grocery industry's profitability. The lack of evidence-based information regarding causes of employee turnover may result in senior level leadership within the retail grocery industry formulating retention strategies based upon conjecture. Basing retention strategies on turnover misconceptions may be costly and actually fail to reduce turnover. For these reasons, this study sought to fill the knowledge gap by providing the grocery industry with evidence-based information on the topic of employee turnover. In an effort to provide a better understanding of the factors that support an engaged workforce, data from 151 frontline retail grocery employees' gathered perceptions of their work environment, burnout, and turnover intentions. The participating employees represented one grocery chain in Western New York. The key finding was that value conflicts have a strong, statistically significant relationship with cynicism, which in turn increases the likelihood for employee turnover. Making use of this evidence-based information may help in creating strategies for a more engaged workforce and retaining the most valuable employees.
\end{abstract}

Keywords: Employee Turnover; Burnout; Employee Engagement

\section{INTRODUCTION}

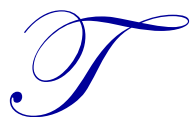

urnover is relatively high in the retail grocery industry. The Bureau of Labor Statistics (2013) reported that the annual turnover rate in this industry was $26.8 \%$ compared to the national average at $18.8 \%$. While turnover is endemic in this industry, few researchers have explored the early warning signs of turnover in retail sales (Friend, Hamwi, Hartmann, \& Rutherford, 2011). The scarcity of evidence-based information may influence senior leadership to base their retention strategies on misconceptions. Senior leaders should avoid formulating retention strategies on assumption; therefore, leadership should formulate strategies based on the best scientific information available (Rousseau, 2006). This paper provided evidence-based information by showing how the employees' work environment and perception of burnout relates to their turnover intentions. This paper also discusses why the servant leadership is suitable to reduce burnout and increase employee retention.

\section{THE PROBLEM (TURNOVER IS COSTLY)}

Turnover costs organizations time, money, and production and have direct and indirect effects on an organization's bottom line. The direct costs of turnover are payment of accrued vacation time to the departed employee and replacement costs (e.g., employee agency fees, advertising, training, relocating distant employees, and orientation time). The indirect costs of turnover are low morale, lost skill sets, disgruntled customers, and lost networks (Wallace \& Gaylor, 2012). Frank (2000) maintained that the average turnover cost for a retail grocery store each year is $\$ 190,000$. In regards to the average turnover costs per position, turnover may cost a grocery chain $16 \%$ to $20.4 \%$ of an employees' annual salary (Boushey \& Glynn, 2012). Figure 1 is an illustration of the average turnover cost per position. 


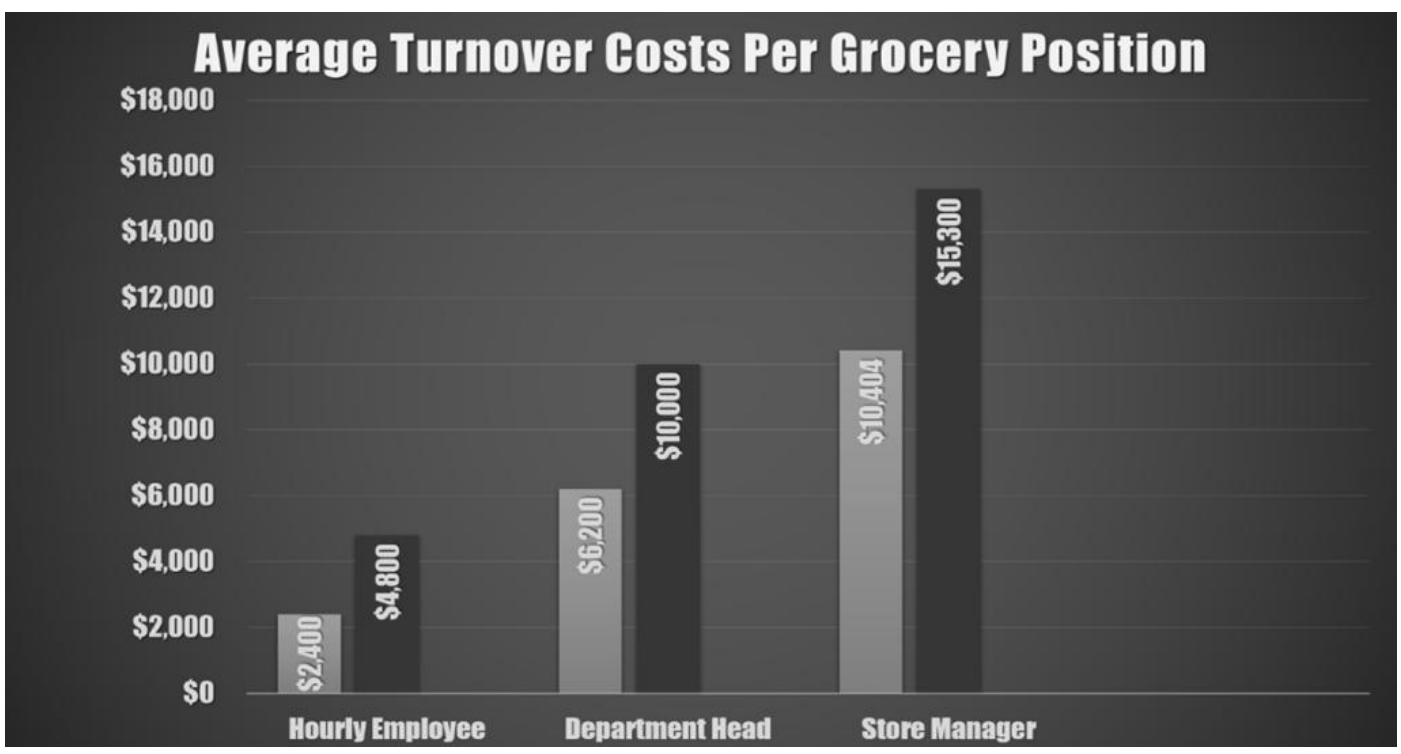

Figure 1: Average Turnover Cost per Grocery Position

\section{MISCONCEPTIONS OF TURNOVER AND PURPOSE OF THE STUDY}

A paucity of evidence-based information may cause senior leaders to build retention strategies on misconceptions of turnover. The most common misconceptions of turnover are that (a) people leave organizations because of their pay, (b) people leave their company because of dissatisfaction, (c) managers can do very little to prevent turnover, (d) one-size fit all retention strategies are effective. Basing retention strategies on any of these turnover misconceptions could be costly while failing to produce the desired results (Allen, Bryant, \& Vardaman, 2010). The purpose of this research was to provide senior leaders in retail grocery with evidence-based information by determining the statistically significant relationships between employees' perception of their work environment, burnout, and their intentions to quit their organization.

\section{THEORETICAL FRAMEWORK (BURNOUT PHENOMENON)}

Researchers linked burnout to work-related outcomes such as job turnover (Herda \& Lavelle, 2012; Leiter \& Maslach, 2009; Schaufeli \& Bakker, 2004). Burnout is chronic stress that an employee may experience on the job (Wallbank \& Hatton, 2011). Queiros, Carlotto, Kaiseler, Dias, and Pereira (2013) described burnout as emotional exhaustion, cynicism, and inefficacy. Emotional exhaustion is a feeling of mental fatigue. Employees experience cynicism when they distrust the company and fellow workers and show anger and resentment against the organization. Inefficacy is the employees' personal belief that they are not able to make any meaningful contributions to their job (Beheshtifar \& Omidvar, 2013).

\section{THE CAUSE OF BURNOUT}

Employees may experience burnout when there is a mismatch between any area of the work environment and the employees' perception about their job. The critical areas of the work environment where mismatches may occur are workload, community, control, reward, fairness, and values. Workload is the amount of work that an employee can handle in a given time. Community is the relationships that employees have with their fellow coworkers and their managers. Control is the ability to make decisions or meaningful contributions to achieve the company's objectives. Reward is the monetary and non-monetary reward a person may receive for successfully fulfilling a task. Fairness is the perception that managers treat their employees equally and treat their employees with trust and respect. Values are the beliefs that individuals hold to be true (Leiter \& Maslach, 2011).

The greater the mismatch between any area of the work environment and the person, the more likely he or she may experience burnout. In contrast, an alignment between the person and his or her work environment 
increases the likelihood for job engagement. Sardeshmukh, Sharma, and Golden (2012) described job engagement as high energy, strong involvement, and efficacy. Employees demonstrate high energy by persevering under tough circumstances while investing total effort into their job. Strong involvement is a sense of inspiration, significance, and enthusiasm while efficacy is the belief that employees have control over their work.

\section{METHOD}

This study made use of structural equation modeling (SEM) to determine if burnout plays a mediating role in frontline retail employees' intention to quit. Researchers use SEM to test a hypothesized model and use path coefficients and probability values to determine the strength of association between variables. One of the advantages of SEM is that this tool is effective against multicollinearity. Multicollinearity occurs when variables are highly correlated. Highly correlated variables add little value to the statistical model (Polit, 2010).

\section{HYPOTHESIS (THE EMPLOYEES' WORK ENVIRONMENT HAS A STATISTICALLY SIGNIFICANT RELATIONSHIP WITH BURNOUT AND TURNOVER INTENTIONS)}

Leiter and Maslach (2009) projected that control predicts workload, fairness, community, and rewards. Fairness, community, and rewards are set to predict values, which in turn should predict each burnout dimension. Finally, burnout predicts the employees' intention to quit. Figure 2 is a display of the hypothesized mediation model.

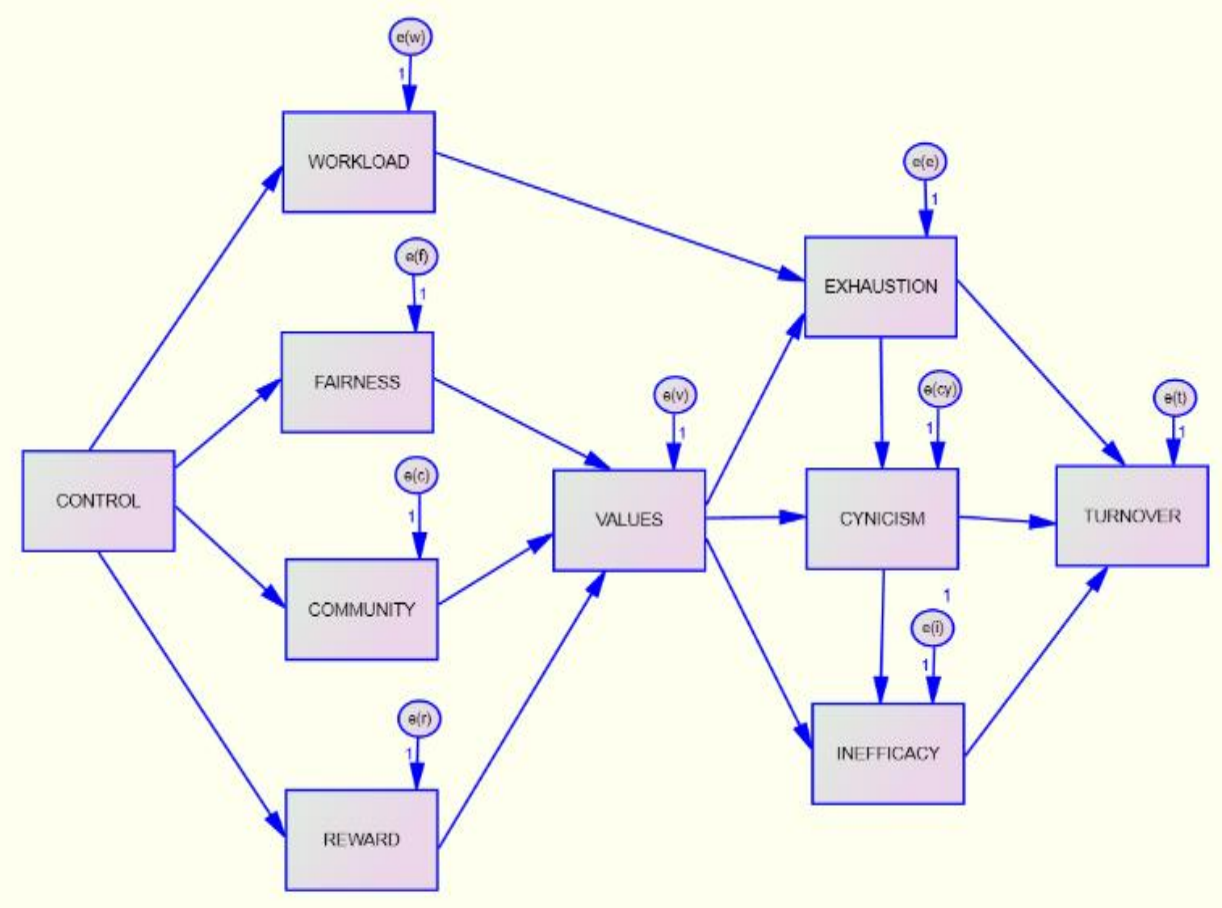

Figure 2: Hypothesized Mediation Model

\section{INSTRUMENTATION}

This research used the Maslach Burnout Inventory- General Survey (MBI-GS), the Areas of Worklife Survey $5^{\text {th }}$ edition (AWS), and Kelloway, Gottlieb, and Barham (1999) Turnover Intentions survey (KGB-TIS). The MBI-GS, measures the dimensions of burnout (i.e., emotional exhaustion, cynicism, and inefficacy). The AWS 
measures the employees' perceptions of their work environment. Last, the KGB-TIS assess the employees' turnover intentions.

\section{MBI-GS}

The MBI-GS assesses the dimensions of burnout on a 7-point Likert scale ranging from zero (never) to 6 (every day) (Maslach, Jackson, Schaufeli, \& Schwab, 1996).

Scoring for the MBI-GS involved calculating the mean scores for each burnout dimension.

Sample Items for the MBI-GS:

1. I feel emotionally drained from my work.

2. I feel used up at the end of my workday.

3. I feel tired when I get up in the morning and have to face another day on the job.

\section{AWS}

The AWS is a 28-item measure that assesses the six areas of the work environment. Study participants can indicate their degree of agreement on a 5-point Likert scale that ranges from 1 (strongly disagree), through 3 (hard to decide), to 5 (strongly agree) (Leiter \& Maslach, 2011).

Sample Items for the AWS

1. I do not have time to do the work that must be done.

2. I work intensely for prolonged periods of time.

3. I have so much work to do on the job that it takes me away from my personal interests.

\section{KGB-TIS}

On a 5 -point Likert scale $(1=$ strongly disagree to $5=$ strongly agree $)$, the KGB- TIS captures the frontline grocery employees' turnover intentions.

Sample Items for the KGB-TIS

1. I am thinking about leaving this organization.

2. I am planning to look for a new job.

3. I intend to ask people about new job opportunities.

4. I do not plan to be in this organization much longer.

\section{MEASUREMENT RELIABILITY AND VALIDITY}

Each instrument used in this study was reliable. Maslach and Leiter (2009) established reliability for the MBI-GS and the AWS by reporting acceptable Cronbach's alpha scores in a study of 667 nurses in Canada: exhaustion $(\alpha=0.89)$, cynicism $(\alpha=0.89)$, inefficacy $(\alpha=0.92)$, workload $(\alpha=0.85)$, control $(\alpha=0.70)$, reward $(\alpha$ $=0.82)$, community $(\alpha=0.80)$, fairness $(\alpha=0.77)$, and values $(\alpha=.82)$. Kelloway et al. (1999) reported acceptable Cronbach's alpha scores in a study of 236 employees from various industries in Western and Ontario, Canada: turnover intentions $(\alpha=.92)$. This study used Pearson's $r$ to evaluate predictive validity.

\section{SAMPLE POPULATION, DEMOGRAPHIC STATISTICS, AND SAMPLING APPROACH}

The sample population was $151(N=151)$ frontline grocery workers in Western New York. Of those participants, $82(N=82)$ were female while $69(N=69)$ where male. The ages of the participants were 18-19 years $(N=14), 20-24$ years $(N=25), 25-29$ years $(N=15), 30-34$ years $(N=14), 35-39$ years $(N=19), 40-44$ years $(N=$ 
9), 45-49 years $(N=18), 0-54$ years $(\mathrm{N}=19), 55-59$ years $(\mathrm{N}=12), 60-64$ years $(\mathrm{N}=3)$, and 65-69 years $(\mathrm{N}=3)$. The number of full-time employees was $85(N=85)$. The number of part-time employees was $66(N=66)$. The job types represented management $(N=75)$ and non-management $(N=76)$. The years of experience for the participants were less than a year $(N=9), 1-2$ years $(N=14), 3-5$ years $(N=20), 6-10$ years $(N=32), 11-15$ years $(N=14), 16$ 20 years $(N=19)$, and 20 or more years $(\mathrm{N}=43)$. This study made use of a non-probability sampling approach, which the researcher selects participants because they represent some characteristics of what the study explores (Creswell, 2008). Participation in this study was voluntary and participants had the right to withdraw at any time.

\section{DATA ANALYSIS}

The Cronbach's alpha score for each variable were reliable. These scores indicate internal consistency among scores in subscales. Table 1 lists the descriptive statistics and Cronbach's alpha scores for burnout, work environment, and turnover intention variables.

Table 1: Descriptive Statistics and Cronbach's Alpha Scores for Burnout, Work Environment, and Turnover Intention Variables $(\mathbf{n}=\mathbf{1 5 1})$

\begin{tabular}{lcccc}
\hline \multicolumn{1}{c}{ Variables } & Mean & SD & $\boldsymbol{\alpha}$ & \#Items \\
\hline Exhaustion & 2.2000 & 1.57852 & 0.87 & 4 \\
Cynicism & 1.5550 & 1.44613 & 0.84 & 5 \\
Inefficacy & .8278 & .93856 & 0.77 & 6 \\
Workload & 2.6662 & .77828 & 0.70 & 5 \\
Control & 3.5778 & .79330 & 0.79 & 4 \\
Reward & 3.3543 & .90340 & 0.88 & 4 \\
Community & 3.6914 & .72874 & 0.82 & 5 \\
Fairness & 3.2130 & .75772 & 0.78 & 6 \\
Values & 3.6705 & .76178 & 0.85 & 4 \\
Turnover & 1.9719 & 1.04982 & 0.93 & 4 \\
\hline
\end{tabular}

\section{RESULTS}

\section{Hypothesis: The Relationships between Work Environment, Burnout, and Turnover Intentions}

The hypothesis addressed the relationship between the employees' work environment, burnout, and their intentions to leave the organization. The path between control and community was statistically significant at (.558, $p<.01)$. The path between control and fairness was statistically significant at $(.417, p<.05)$. The path between control and reward was statistically significant at $(.370, p<.01)$. The path between values and community $(.265, p$ $<.05)$, values and fairness $(.417, p<.01)$, values and reward $(.205, p<.05)$, and values and cynicism $(-.317, p<$ $.05)$ were statistically significant. The path between cynicism and turnover intentions were also statistically significant $(.399, p<.01)$.

The model revealed an alternative path to turnover intentions. Control had a minor influence on workload $(-.217, p<.05)$. Workload's association with emotional exhaustion was strong at $(.356, p<.01)$. Emotional exhaustion mediated cynicism, which in turn predicted the employees' intention to leave $(.399, p<.01)$. Table 2 is a display of the standardized regression weights and $p$-values of the mediation model. Figure 3 is an illustration of the tested mediation model.

Table 2: Standardized Regression Weights and P-Values for the Hypothesized Mediation Model

\begin{tabular}{|lcl|cccc|}
\hline & Parameter & & Estimate & Lower & Upper & P \\
\hline fairness_average & $<---$ & control_average & .417 & .281 & .531 & .013 \\
community_average & $<---$ & control_average & .558 & .445 & .659 & .008 \\
reward_average & $<---$ & control_average & .370 & .246 & .488 & .008 \\
workload_average & $<---$ & control_average & -.217 & -.378 & -.089 & .011 \\
values_average & $<---$ & fairness_average & .417 & .258 & .542 & .013 \\
values_average & $<---$ & community_average & .265 & .082 & .424 & .011 \\
values_average & $<---$ & reward_average & .205 & .056 & .361 & .027 \\
\hline
\end{tabular}


Table 2 cont.

\begin{tabular}{|llc|cccc|}
\hline exhaustion_average & $<---$ & workload_average & .356 & .218 & .511 & .006 \\
exhaustion_average & $<---$ & values_average & -.283 & -.414 & -.136 & .025 \\
cynicism_average & $<---$ & exhaustion_average & .593 & .488 & .693 & .009 \\
cynicism_average & $<---$ & values_average & -.317 & -.415 & -.203 \\
inefficacy_average & $<---$ & cynicism_average & .307 & .016 \\
inefficacy_average & $<---$ & values_average & -.122 & -.269 & .429 & .012 \\
turnover_average & $<---$ & exhaustion_average & -.115 & -.293 & .006 & .112 \\
turnover_average & $<---$ & inefficacy_average & .162 & -.013 & .288 \\
turnover_average & $<---$ & cynicism_average & .399 & .184 & .601 & .009 \\
\hline
\end{tabular}

Statistically Significant at $* * * p<.001, * * p<.01, * \mathrm{p}<.05$

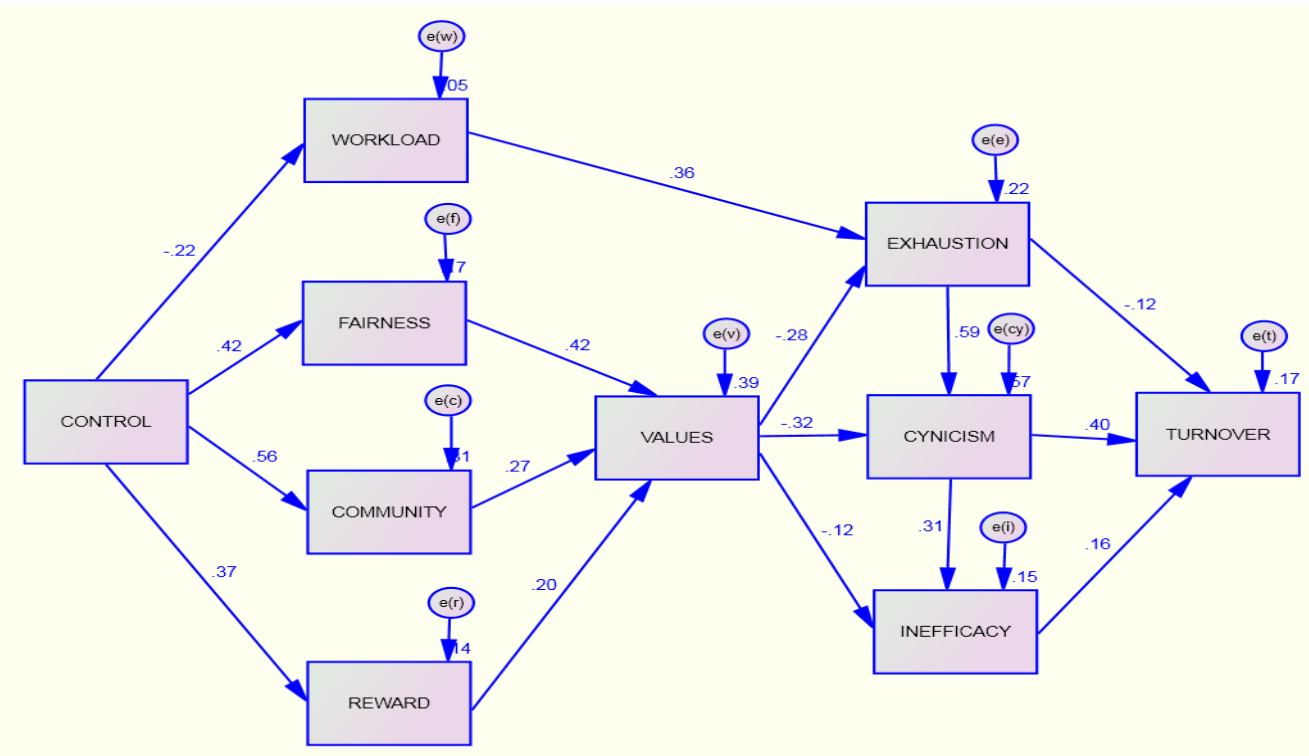

Figure 3: Tested Mediation Model with Path Coefficients

\section{DISCUSSION}

This study provided insight regarding how the intention of grocery employees to leave their job relates to particular characteristics of the work environment and burnout. The insights in this study may provide senior leadership with areas to target for early intervention strategies to build a more engaging workforce and prevent an early exit from the grocery industry.

The findings determined that an employee's sense of control is at the hub of both pathways to turnover. The first path revealed that an employee's sense of control fostered feelings of community, fairness, and reward. Moreover, community, fairness, and reward shape the values of the employee. Values had a significantly strong correlation with cynicism. Cynicism, in turn, creates an incubator for turnover. The second path to burnout showed that an employee's sense of control influences his or her perception of workload. This path also revealed that workload and exhaustion are correlated significantly. Emotional exhaustion predicted cynicism, which in turn predicted turnover intent among retail grocery workers. For a retail chain, creating retention strategies that focus on these aspects of the work environment may curtail cynicism, which in turn may help retain the most valuable employees (Leiter \& Maslach, 2009) while providing the company with a competitive advantage (Bakker, Schaufeli, Leiter, \& Taris, 2008). 


\section{LIMITATIONS}

One of the limitations in this study was that of data collection. Findings in a particular geographic location may not be generalizable other grocery chains in the United States. The second limitation was that although quantitative studies are well suited for describing the relationships between variables, this particular method is not applicable for an in-depth exploration of the burnout phenomena.

\section{RECOMMENDATIONS FOR LEADERSHIP}

Employing the appropriate leadership style is vital for preventing high levels of burnout and cultivating an engaging culture. Researchers determined that the servant style of leadership is an effective organizational resource to reduce burnout and turnover (Babakus, Yavas, \& Ashill, 2011; Jaramillo, Grisaffe, Chonko, \& Roberts, 2009; Jones, 2012). Because of its strong, negative correlation with burnout and turnover intentions, the servant style of leadership is conducive for engagement (Babakus et al., 2011; Jones, 2012). Servant leaders nurture motivation, self-efficacy, and teach followers to become servant leaders (Babakus et al., 2011). Servant leaders focus on placing the needs of their subordinates over their own needs, share decision-making power, and build a strong sense of community at every level of the organization (Smith, 2009). Because of the nature of this style of leadership, followers may demonstrate a strong desire to serve customers. A strong desire to serve customers increases customer satisfaction (Marrelli, 2011). Greenleaf (as cited in Smith, 2009) opined that the characteristics of servant leaders are the following:

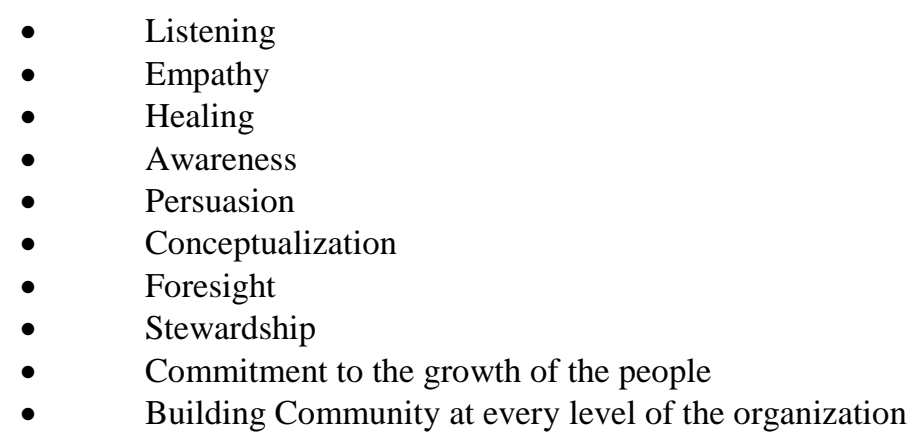

\section{AUTHOR INFORMATION}

Steven Harrison, DBA, University of Phoenix, 1327 S. Woodcreek Lane, Florence, SC 29506 USA. E-mail: Harris2959@hotmail.com

Pamela Ann Gordon, Ph.D., University of Phoenix, 1470 S.W. $164^{\text {th }}$ Avenue, Pembroke Pines, Florida 33027 USA. E-mail: Pam.Gordon@phoenix.edu (Corresponding author)

\section{REFERENCES}

1. Allen, D. G., Bryant, P. C., \& Vardaman, J. M. (2010). Retaining talent: Replacing misconceptions with evidence-based strategies. Academy of Management Perspectives, 24(2), 48-64.

2. Babakus, E., Yavas, U., \& Ashill, N. J. (2011). Service worker burnout and turnover intentions: Roles of person-job fit, servant leadership, and customer orientation. Services Marketing Quarterly, 32(1), 17-31. doi:10.1080/15332969.2011.533091

3. Bakker, A., Schaufeli, W., Leiter, M., \& Taris, T. (2008). Work engagement: An emerging concept in occupational health psychology. Work \& Stress, 22(3), 187-200. Retrieved from EBSCOhost.

4. Beheshtifar, M., \& Omidvar, A. R. (2013, June). Causes to create job burnout in organizations. International Journal of Academic Research in Business and Social Sciences, 3(6), 107-113.

5. Bureau of Labor Statistics (2013). Databases, tables and calculators by subject. Retrieved from http://www.bls.gov/data/\#historical-tables 
6. Creswell, J. (2008). Educational research: Planning, conducting, and evaluating quantitative and qualitative research (3rd ed.). Upper Saddle River, NJ: Pearson Merrill Prentice Hall.

7. Friend, S. B., Hamwi, G., Hartmann, N. N., \& Rutherford, B. N. (2011). Measuring salesperson burnout: A reduced Maslach burnout inventory for sales researchers. Journal of Personal Selling \& Sales Management, 31(4), 429-440.

8. Herda, D. N., \& Lavelle, J. J. (2012). The auditor-audit firm relationship and its effect on burnout and turnover intention. Accounting Horizons, 26(4), 707-723. doi:10.2308/acch-50181

9. Jaramillo, F., Grisaffe, D. B., Chonko, L. B., \& Roberts, J. A. (2009). Examining the impact of servant leadership on salesperson's turnover intention. Journal of Personal Selling \& Sales Management, 29(4), 351-365.

10. Jones, D. (2012). Servant leadership's impact on profit, employee satisfaction, and empowerment within the framework within the framework of a participative culture in business. Business Studies Journal, 4(1), 35-49.

11. Kelloway, E., Gottlieb, B., \& Barham, L. (1999). The source, nature, and direction of work and family conflict: A longitudinal investigation. Journal of Occupational Health Psychology, 4(4), 337-346.

12. Leiter, M. P., \& Maslach, C. (2009). Nurse turnover: The mediating role of burnout. Journal of Nursing Management, 17(3), 331-339. doi:10.1111/j.1365-2834.2009.01004.x

13. Leiter, M. P., \& Maslach, C. (2011). Areas of worklife survey manual (5th ed.). Menlo Park, CA: Mind Garden.

14. Marrelli, A. (2011). Employee engagement and performance management in the federal sector. Performance Improvement, 50(5), 5-13. doi:10.1002/pfi.20216

15. Maslach, C. (n.d). Preventing burnout and building engagement. Washington, District of Columbia, US: American Psychological Association.

16. Maslach, C., Jackson, S., Schaufeli, W., \& Schwab, R. (1996). MBI: The Maslach Burnout Inventory: Manual. Palo Alto: Consulting Psychologists Press.

17. Melchar, D. E., Bosco, S. M., \& Cantrell, C. (2008, June). Leadership for the next generation. Proceedings For The Northeast Region Decision Sciences Institute (NEDSI), 498-503.

18. Queiros, C., Carlotto, M. S., Kaiseler, M., Dias, S., \& Pereira, A. M. (2013, August). Predictors of burnout among nurses: An interactionist approach. Psicothema, 25(3), 330-335.

19. Rousseau, D. M. (2006). Is there such a thing as "evidence-based management"? Academy of Management Review, 31(2), 256-269. doi:10.5465/AMR.2006.20208679

20. Sardeshmukh, S. R., Sharma, D., Golden, T. D. (2012, November). Impact of telework on exhaustion and job engagement: A job demands and job resources model. New Technology, Work, \& Employment, 27(3), 193-207.

21. Schaufeli, W. B., \& Bakker, A. B. (2004). Job demands, job resources, and their relationship with burnout and engagement: A multi-sample study. Journal of Organizational Behavior, 25, 293-315.

22. Smith, C. (2009). Servant leadership: The leadership theory of Robert K. Greenleaf. Info 640- Mgmt. of info. Orgs. Retrieved from http://carolsmith.us/downloads/640greenleaf.pdf

23. Wallace, J., \& Gaylor, K. P. (2012). A study of the dysfunctional and functional aspects of voluntary employee turnover. SAM Advanced Management Journal, 77(3), 27-36. 